Nevşehir Bilim ve Teknoloji Dergisi TARGíd Özel Sayı 144-149 2016

DOI: 10.17100/nevbiltek.210980

URL: http://dx.doi.org/10.17100/nevbiltek.210980

\title{
Türkiye’nin Avrupa Birliği Şarap Pazarında Rekabet Gücü
}

\author{
Hülya Uysal $^{1, *}$, Gamze Saner ${ }^{2}$, Ela Atış ${ }^{2}$, Sevtap Gümüş ${ }^{2}$, Selçuk Karabat ${ }^{1}$ \\ ${ }^{1}$ Bağcılık Araştırma Enstitüsü Müdürlüğü, Manisa \\ ${ }^{2}$ Ege Üniversitesi Ziraat Fakültesi Tarım Ekonomisi Bölümü, IZZMiR
}

Öz

Türkiye coğrafi açıdan, uygun toprak ve iklim koşullarına sahip olmasından dolayı kaliteli ve farklı şaraplık üzüm çeşitlerinin üretilebileceği bir ülkedir. Ancak şaraplık üzüm üretimi yıllar içerisinde ihmal edilmiştir. Türkiye'de üretilen üzümün, sadece \%2,5-3'lük bölümü şaraplık olarak değerlendirilmektedir. Bu çalışmada; Türkiye'nin Avrupa Birliği (AB) şarap pazarındaki rekabet gücünün belirlenmesi amaçlanmıştır. Çalışmada 2000-2014 dönemine ilişkin makro ekonomik veriler kullanılmış ve analizlerde “Açıklanmış Karşılaştırmalı Üstünlükler” (AKÜ) indeksinden yararlanılmıştır. AKÜ-Balassa indeksi ile ilgili bulgulara bakıldığında Türkiye'nin Avrupa Birliği pazarındaki şarap dış satımında, Almanya’ya karşı rekabet gücünün bulunduğu sonucuna varılmıştır. Belçika, Hollanda, Fransa, İtalya, İspanya gibi diğer ülkelerin karşısında ise rekabet gücünün kalmadığı belirlenmiştir.

Anahtar Kelimeler: Şaraplık üzüm, Rekabet gücü, AKÜ-Balassa indeksi, Türkiye, Avrupa Birliği

\section{Competitiveness of Turkey in the European Union Wine Market}

Abstract

Geographically, Turkey has the most suitable soil and climatic conditions for growing quality and different wine grape varieties. However wine grape growing has been neglected for many years. It is estimated that 2,5-3\% of grape production devoted to making wine.

The aim of this study is to determine Turkey's comparative advantage and international competitiveness in the EU wine market. In this study macro-economic data were used for the period 2000-2014. The analysis is based on Balassa's (1965) "Revealed Comparative Advantage (RCA) index. The analysis based on Balassa's indices shows that Turkey has a comparative advantage oriented to German wine market. Turkey has accordingly got the revealed comparative disadvantages against other countries (Belgium, Holland, France, Spain, Italy).

Keywords: Wine grape, Competitiveness, RCA- Balassa indice, Turkey, European Union

*e-mail: hulya.uysal@gthb.gov.tr 


\section{Giriş}

Dünya bağcılığında 468.792 hektarlık bağ alanı ile İspanya, Fransa, Çin, İtalya ve Güney Afrika'dan sonra 6. sırada bulunan Türkiye; 4.011.409 ton üzüm üretimi ile 77.181.122 tonluk dünya üzüm üretimi içerisinde; Çin, İtalya, ABD, İspanya ve Fransa'nın ardından 6. sırada $(\% 5,20)$ yer almaktadır [1]. Dünyada üretilen üzümün \%71'i şaraplık, \%27'si sofralık ve \%2'si kurutmalık olarak değerlendirilmektedir [2]. Türkiye'de ise üretilen üzümün \%37'si çekirdekli ve çekirdeksiz kurutmalık, $\% 52$ 'si sofralık, \%11'ide şaraplık olarak değerlendirilmektedir [3]. Şaraplık üzümler, kıraç alanlarda kullanılmayan tarım arazilerinde üretilebilmekte ve diğer tarım ürünlerine oranla daha yüksek fiyatla satılabilmektedir. Üzümlerin şaraba işlenmesi sırasında birçok iş kolu devreye girmektedir. Dolayısıyla ülkeye kazandırdığı katma değer, birçok tarım ürününe göre daha yüksek olmaktadır. Emek yoğun bir tarımsal faaliyet olan şaraplık üzüm üretimi istihdam açısından da ekonomiye önemli katkılar sağlamaktadır.

Dünya şarap üretiminde, tüketiminde, dış satım ve dış alımında $A B$ lider konumdadır. $A B$ içerisinde ise Fransa, İtalya ve İspanya lider ülkelerdir [1]. Dünya şarap dış satımında AB ülkelerinin payı \%71,1'dir. Türkiye'nin 3.466 ton olan şarap dış satımı ve bu dış satımdan elde ettiği 7.360.000 \$'lık gelir dünyadaki bağcılıkla uğraşan diğer ülkelerle karşılaştıııldığında yok denecek kadar azdır [1].

Dış pazarda 1 milyon ton dolayında şarap dış satımı yapılmakta olup değeri 29 milyar \$'dır [1]. Türkiye şaraplık üzüm üretim miktarının düşük olması nedeniyle; dış pazarda ve aynı zamanda $A B$ pazarında da söz sahibi değildir. Şaraplık üzüm üretimi; Türkiye'de yıllar içerisinde ihmal edilirken, özellikle Avrupa ülkelerinin yerel ve bölgesel anlamdaki tarımsal ve dolayısıyla da ekonomik kalkınmalarında önemli rol oynamıştır. AB ülkelerinde, Ortak Tarım Politikası (OTP) çerçevesinde, bağcılık ve şarap sektörü en çok önemsenen ve korunan sektörlerden birisi olarak ele alınmaktadır [4]. 1493/1999/EC sayılı AB tüzüğü ile oluşturulan şarap ortak piyasa düzeni ile Birlik pazarında arz ve talep arasında daha iyi bir denge oluşturmak ve sektörün daha rekabetçi olmasına olanak sağlamak hedeflenmiş̧tir. Türkiye’nin de AB'ne üyeliği gerçekleştiği durumda mevcut alanlar sınırlandırılabilecek ve şaraplık üzüm üreticileri yönünde haksız rekabet olabilecektir. Bu çalışmanın amacı, Türkiye'nin kaliteli şaraplık çeşitlerinin Avrupa Birliği pazarında yer alan üye ülkeler karşısındaki pazar payı açısından mevcut rekabet gücünü belirlemek ve gelecek için bir potansiyelinin olup olmadığını ortaya koymaktır. Bu amaca yönelik olarak rakip AB ülkeleri ile Türkiye'nin şarap dış satımını yaptığı ülkeler açısından rekabet gücünün düzeyi ölçülmüştür.

\section{Materyal ve Metot}

Bu çalışmada Türkiye'nin şarap dış satımını yaptığı ülkelerden; Almanya, Belçika, Hollanda ile AB şarap pazarında söz sahibi olan ülkelerden; Fransa, İtalya, İspanya çalışma kapsamına alınmıştır.

Türkiye’nin, belirlenen ülkeler karşısında Avrupa Birliği pazarındaki rekabet gücü açısından değerlendirmeler yapılırken; Açıklanabilir Karşılaştırmalı Üstünlükler (AKÜ) indeksinden yararlanılmış ve 2000-2014 yıllarına ait veriler kullanılmıştır. "Bir ülkenin mal bazındaki dış satımının yapısı, o ülkenin karşılaştırmalı avantajını, dış alımının yapısı ise dezavantajını yansıtır" varsayımından hareketle oluşturulan AKÜ indekslerinden ilki, Balassa tarafindan önerilen AKÜ-Balassa indeksidir. Bu indeks, 
mal gruplarının dış satım içindeki paylarının dış alım içindeki paylarına oranını göstermektedir ve net dış satım oranına göre aşağıda verilen formülle hesaplanmaktadır [5].

AKÜ-Balassa $=\ln \{(\mathrm{Xi} / \mathrm{X}) /(\mathrm{Mi} / \mathrm{M})\} * 100$

Burada,

Xi: i mal grubunda karşılaştırılan ülkeye yapılan dış satım değeri

$\mathrm{X}$ : Karşılaştırılan ülkeye yapılan toplam dış satım değeri

Mi: i mal grubunda karşılaştırılan ülkeden yapılan dış alım değeri

M: Karşılaştırılan ülkeden yapılan toplam dış alım değeri

AKÜ-Balassa indeksinin sıfirdan büyük çıkması, ilgili mal ya da sektörde, oransal olarak, dış alımdan daha fazla dış satım yapılmakta olduğu anlamına gelmekte ve bu durum, söz konusu mal ya da sektörde ülkenin açıklanmış karşılaştırmalı üstünlüğe sahip olduğu şeklinde yorumlanmaktadır. Tersi durum ise, ilgili ülkenin açıklanmış karşılaştırmalı dezavantaja sahip olduğunu göstermektedir.

\section{Bulgular}

Açıklanabilir Karşılaştırmalı Üstünlükler İndeksi ile Türkiye’nin Avrupa Birliği Pazarındaki Rekabet Gücü

Rekabet gücü; bir sektörün rakipler karşısında pazar payı elde etmesi ve bu payı karlı bir şekilde koruyabilmesi şeklinde tanımlanmaktadır [6, 7]. Türkiye ve rakip ülkelerin karlılığı konusunda karşılaştırmaya yönelik verilerin yetersizliği nedeniyle, rekabet gücü, pazar payına yönelik değişkenler yolu ile belirlenmiştir. Bu çerçevede Türkiye'nin şarap dış satımını yaptığı ülkelerden Almanya, Belçika, Hollanda ile $\mathrm{AB}$ şarap pazarında söz sahibi olan ülkelerden Fransa, İtalya, İspanya karşısında rekabet gücünün düzeyi ölçülmüştür. Açıklanmış karşılaştırmalı üstünlükler (AKÜ) yaklaşımı, rekabet gücünü ölçmede oldukça sık kullanılan yöntemlerden biridir. Bir ülkenin mal ya da sektör bazındaki dış satım yapısının ülkenin karşılaştırmalı üstünlüklerini, dış alım yapısının ise karşılaştırmalı dezavantajlarını yansıttığı AKÜ yaklaşımına göre; bir malın ticaret dengesinin pozitif olması durumunda o ülkenin o malın/sektörün dış satımında karşılaştırmalı üstünlüğe, tersi durumda ise rekabet gücünden yoksunluğa sahip olduğu söylenebilir [8].

Türkiye’nin $\mathrm{AB}$ şarap pazarındaki rekabet gücü düzeyini belirleyebilmek için öncelikli olarak seçilen ülkelere yapılan şarap dış satım değeri ile bu ülkelerle yapılan toplam dış satım değerlerine ait veriler elde edilmiştir [3]. İncelenen dönemde Türkiye’nin AB ülkelerine yönelik dış satımının artış gösterdiği belirlenmiştir. Türkiye'nin AB ülkelerine yaptığı toplam dış satım değerine bakıldığında en fazla dış satım değerinin Almanya'dan elde edildiği görülmektedir. Türkiye'nin AB'ne şarap dış satımında ise Belçika ilk sırada yer almaktadır. İncelenen dönem içerisinde bu ülkelere yapılan toplam dış satım değerinde artış söz konusu iken şarap dış satımında ise bir gelişmenin olmadığı belirlenmiştir (Çizelge 1). 
Çizelge 1. Karşılaştırılan Ülkelerle Türkiye'nin Şarap Dış Satımı ile Toplam Dış Satım Durumu (1000 \$)

\begin{tabular}{|c|c|c|c|c|c|c|c|c|c|c|c|c|}
\hline \multirow{2}{*}{ İhracat } & \multicolumn{2}{|c|}{ Almanya } & \multicolumn{2}{|c|}{ Belçika } & \multicolumn{2}{|c|}{ Hollanda } & \multicolumn{2}{|c|}{ Fransa } & \multicolumn{2}{|c|}{ İtalya } & \multicolumn{2}{|c|}{ İspanya } \\
\hline & Şarap & Toplam & Şarap & Toplam & Şarap & Toplam & Şarap & Toplam & Şarap & Toplam & Şarap & Toplam \\
\hline 2000 & 2.094 & 5.179 .844 & 1.352 & 647.073 & 95 & 874.182 & 1.162 & 1.656 .968 & - & 1.789.307 & - & 712.889 \\
\hline 2001 & 1.696 & 5.366 .945 & 1.104 & 688.261 & 70 & 892.416 & 620 & 1.895 .290 & 316 & 2.342.186 & - & 950.362 \\
\hline 2002 & 1.726 & 5.868 .813 & - & 693.347 & 69 & 1.055 .637 & 1.017 & 2.134 .575 & - & 2.375 .692 & 2 & 1.125 .072 \\
\hline 2003 & 2.164 & 7.484 .931 & - & 885.564 & 85 & 1.525 .929 & 497 & 2.826 .141 & - & 3.193.242 & - & 1.789 .497 \\
\hline 2004 & 2.235 & 8.745.282 & - & 1.183.181 & 66 & 2.138 .004 & 283 & 3.668 .418 & 11 & 4.648 .475 & 29 & 2.619.784 \\
\hline 2005 & 2.535 & 9.455 .050 & 1.828 & 1.292 .264 & 59 & 2.469 .582 & 228 & 3.805 .760 & - & 5.616 .755 & - & 3.010 .857 \\
\hline 2006 & 1.368 & 9.686 .235 & 1.851 & 1.381 .104 & 70 & 2.539.246 & 151 & 4.604 .349 & - & 6.752 .346 & - & 3.720 .458 \\
\hline 2007 & 1.279 & 11.993.232 & 1.223 & 1.735 .798 & 87 & 3.018.878 & 668 & 5.974 .462 & - & 7.480 .060 & 8 & 4.579 .995 \\
\hline 2008 & 1.178 & 12.951 .755 & 2.136 & 2.122 .434 & 136 & 3.143 .835 & 136 & 6.617.511 & - & 7.818.988 & - & 4.047 .267 \\
\hline 2009 & 1.129 & 9.793 .006 & 2.028 & 1.795 .682 & 23 & 2.127.297 & 130 & 6.211 .415 & - & 5.888 .958 & - & 2.818 .470 \\
\hline 2010 & 739 & 11.479 .066 & 1.700 & 1.960 .441 & 70 & 2.461.371 & 100 & 6.054 .499 & 4 & 6.505 .277 & - & 3.536 .205 \\
\hline 2011 & 1.036 & 13.950 .825 & 2.120 & 2.451 .030 & 25 & 3.243 .080 & 127 & 6.805 .821 & - & 7.851 .480 & - & 3.917 .559 \\
\hline 2012 & 978 & 13.126.298 & 2.258 & 2.359.776 & 35 & 3.247 .515 & 54 & 6.199 .068 & 9 & 6.373 .080 & - & 3.717 .345 \\
\hline 2013 & 1.336 & 13.702 .577 & 2.281 & 2.573 .804 & 6 & 3.538 .043 & 135 & 6.376 .704 & 3 & 6.718.355 & - & 4.334.196 \\
\hline 2014 & 1.370 & 15.147 .423 & 2.018 & 2.939.108 & 13 & 3.458 .689 & 66 & 6.464 .243 & 23 & 7.141.071 & - & 4.749 .584 \\
\hline
\end{tabular}

Türkiye’nin seçilen AB ülkeleri ile incelenen dönem içerisinde toplam dış satımında olduğu gibi dış alımında da artış söz konusudur. Şarap sektöründe Fransa'dan yapılan dış alımın artış gösterdiği görülmektedir. Türkiye; Fransa dışında İtalya ve İspanya'dan da şarap dış alımı gerçekleştirmiştir. Son 15 yıl içerisinde Türkiye'nin şarap dış alımında artış olduğu belirlenmiştir (Çizelge 2). Dünyada ve AB içerisinde en büyük üretici ve dış satımcı olan Fransa'da hangi bölgede hangi üzümün yetişeceği, bağ kurma ve bakım yöntemleri, üretim şekilleri, verim gibi kalite şaraplık üzüm üretimlerine yönelik kriterler belirlenmiştir. Ayrıca bağ alanlarının bulunduğu bölgelerin iklim ve toprak yapıları ile şaraplık üzüm çeşitlerinin üretimlerine yönelik düzenlemeleri mevcuttur. 1935 yılında kurulan Kökenli Adlandırma Ulusal Enstitüsü “The National Institute of Appellations of Origin” tarafından üretilen şaraplık üzümlerin gerek doğaya bağlı faktörleri (üzüm türü, iklim, toprak özelliği, güneşlenme şekli vb.) gerekse insana bağl1 faktörleri (bağa uygulanan kültürel işlemler, şaraba işleme şekilleri gibi) belirlenmiştir. Kökeni kontrollü adlandırma "Appelation d'Origine Controlee" (AOC) olarak Fransa'da başlatılan; bu sınıflandırma sistemi üzümlerde ve şaraplarda kaliteyi garanti etmektedir. A.O.C sistemi kaliteli üretimi ve kaliteyi arayan tüketiciyi korumaktadır [9]. Fransa gibi İtalya ve İspanya'da da şaraplık üzüm üretimine ilişkin ülke koşullarına uygun sistemler geliştirilmiş̧ir. Türkiye’nin de kendi koşullarına uygun olacak şekilde şaraplık üzüm çeşitlerinde bölgesel tanımlamalara gitmesi dış pazarda rekabet gücü yaratabilmesi açısından yararlı olacaktır. 
Uysal H., Saner G., Atış E., Gümüş S., Karabat S.

Çizelge 2. Karşıılaştırılan Ülkelerle Türkiye'nin Şarap Dış Alımı ile Toplam Dış Alım Durumu (1000 \$)

\begin{tabular}{|c|c|c|c|c|c|c|c|c|c|c|c|c|}
\hline \multirow[b]{2}{*}{ İthalat } & \multicolumn{2}{|c|}{ Almanya } & \multicolumn{2}{|c|}{ Belçika } & \multicolumn{2}{|c|}{ Hollanda } & \multicolumn{2}{|c|}{ Fransa } & \multicolumn{2}{|c|}{ İtalya } & \multicolumn{2}{|c|}{ İspanya } \\
\hline & Şarap & Toplam & Şarap & Toplam & Şarap & Toplam & Şarap & Toplam & Şarap & Toplam & Şarap & Toplam \\
\hline 2000 & 1 & 7.198.209 & - & 1.660 .618 & 29 & 1.584 .461 & 212 & 3.531 .818 & 44 & 4.332 .788 & 2 & 1.678 .456 \\
\hline 2001 & 1 & 5.335 .443 & 41 & 984.547 & - & 1.041 .587 & 41 & 2.283.939 & 21 & 3.484 .129 & 22 & 1.066 .141 \\
\hline 2002 & - & 7.041 .532 & 23 & 1.150 .015 & - & 1.311 .278 & 68 & 3.052 .706 & 25 & 4.096 .968 & 4 & 1.419 .213 \\
\hline 2003 & 15 & 9.452 .964 & - & 1.523 .584 & - & 1.656 .670 & 51 & 4.164.120 & 46 & 5.471 .537 & - & 2.003 .745 \\
\hline 2004 & 9 & 12.515 .655 & - & 1.991 .728 & - & 1.908 .145 & 328 & 6.201 .348 & 649 & 6.858 .739 & 86 & 3.254 .675 \\
\hline 2005 & - & 13.633 .888 & - & 2.241 .112 & - & 2.151 .585 & 875 & 5.887 .817 & 771 & 7.566 .262 & 147 & 3.555 .106 \\
\hline 2006 & 42 & 14.768 .220 & - & 2.476 .928 & - & 2.160 .110 & 1.111 & 7.239 .953 & 787 & 8.649 .577 & 201 & 3.832 .589 \\
\hline 2007 & 24 & 17.539.955 & - & 2.868 .671 & - & 2.655 .039 & 1.357 & 7.849.709 & 581 & 9.751 .280 & 56 & 4.342.994 \\
\hline 2008 & 84 & 18.687.197 & - & 3.150 .747 & - & 3.056 .340 & 1.328 & 9.022 .015 & 1.239 & 10.682 .037 & 154 & 4.548.182 \\
\hline 2009 & 103 & 14.096 .963 & - & 2.371 .516 & - & 2.543 .073 & 1.205 & 7.091 .795 & 608 & 7.594 .645 & 45 & 3.776.917 \\
\hline 2010 & 91 & 17.549 .112 & - & 3.213 .606 & - & 3.156 .000 & 2.347 & 8.176 .600 & 1.308 & 10.139 .888 & 168 & 4.840 .062 \\
\hline 2011 & 67 & 22.985 .567 & - & 3.959.279 & - & 4.004 .955 & 3.061 & 9.229 .558 & 2.020 & 13.449 .861 & 136 & 6.196 .452 \\
\hline 2012 & 134 & 21.400 .186 & - & 3.690 .309 & - & 3.660 .635 & 4.321 & 8.589.894 & 2.354 & 13.344 .468 & 182 & 6.023 .625 \\
\hline 2013 & 213 & 24.182 .422 & - & 3.843.376 & - & 3.363 .585 & 4.409 & 8.079 .840 & 2.739 & 12.884 .864 & 89 & 6.417 .719 \\
\hline 2014 & 550 & 22.369 .476 & - & 3.863 .892 & - & 3.517 .164 & 8.031 & 8.122 .571 & 3.798 & 12.055 .972 & 386 & 6.075 .843 \\
\hline
\end{tabular}

Çizelge 3'de AKÜ- Balassa'ya göre hesaplanan değerler görülmektedir. AKÜ-Balassa indeksi ile ilgili bulgulara bakıldığında Türkiye'nin Avrupa Birliği pazarında Almanya'ya şarap dış satımında rekabet gücünün bulunduğu anlaşılmaktadır. Diğer ülkeler karşısında Türkiye'nin bazı yıllarda rekabet gücüne sahip olduğu, son dönemlerde ise bu ülkeler karşısında hiçbir rekabet gücünün kalmadığ sonucuna ulaşılmıştır. Karşılaş̧ırılan ülkeden ilgili mala ilişkin dış alım olmaması durumunda indeks değeri tanımsız olmuştur.

Çizelge 3. AB Şarap Dış Alımında Türkiye'nin Rekabet Gücü İndeksi (AKÜ-Balassa)

\begin{tabular}{|c|c|c|c|c|c|c|}
\hline Yıllar & Almanya & Belçika & Hollanda & Fransa & İtalya & İspanya \\
\hline 2000 & 798 & tanımsız & 178 & 246 & tanımsız & tanımsız \\
\hline 2001 & 743 & 365 & tanımsız & 290 & 311 & tanımsız \\
\hline 2002 & tanımsiz & tanimsiz & tanımsız & 306 & tanımsız & -46 \\
\hline 2003 & 521 & tanımsiz & tanımsız & 266 & tanımsız & tanımsız \\
\hline 2004 & 587 & tanımsız & $\operatorname{tanımsız}$ & 38 & -369 & -87 \\
\hline 2005 & tanımsız & tanımsız & $\tan 1 \mathrm{~ms} 1 \mathrm{z}$ & -91 & $\tan ı \mathrm{~ms} 1 \mathrm{z}$ & tanımsız \\
\hline 2006 & 391 & tanımsız & tanımsız & -154 & tanımsız & tanımsız \\
\hline 2007 & 436 & tanımsız & $\tan 1 \mathrm{~ms} 1 \mathrm{z}$ & -44 & $\tan 1 \mathrm{~ms} 1 \mathrm{z}$ & -200 \\
\hline 2008 & 301 & tanımsiz & $\tan ı \mathrm{~ms} 1 \mathrm{z}$ & -197 & $\tan 1 \mathrm{~ms} 1 \mathrm{z}$ & tanımsız \\
\hline 2009 & 276 & tanımsiz & tanımsız & -209 & tanımsiz & tanımsız \\
\hline 2010 & 252 & tanımsız & $\operatorname{tanımsız}$ & -286 & -535 & tanımsız \\
\hline 2011 & 324 & tanımsız & tanımsız & -288 & tanımsız & tanımsız \\
\hline 2012 & 248 & tanımsız & tanımsız & -406 & tanımsız & tanımsız \\
\hline 2013 & 240 & tanımsız & tanımsız & -325 & -617 & tanımsız \\
\hline 2014 & 130 & tanımsız & $\tan 1 \mathrm{~ms} 1 \mathrm{z}$ & -457 & -458 & tanımsız \\
\hline
\end{tabular}




\section{Tartışma ve Sonuç}

Türkiye'nin geleneksel olarak şarap üreten ve dış satım yapan bir ülke olmaması nedeniyle uluslararası piyasalarda belirgin bir payı bulunmamaktadır. AB dış pazarında da Türkiye'nin sadece Almanya karşısında rekabet gücünün bulunduğu sonucuna varılmıştır. Almanya Türkiye'nin dış satımında önemli bir ülkedir. Şaraplık üzüm üretimi yıllar içerisinde ihmal edilmiş olsa da Türkiye, çok sayıda şaraplık üzüm çeşidi ve uygun ekolojisiyle rekabet potansiyeline sahip bulunmaktadır. Ayrıca Türkiye’nin; coğrafi konum, düşük ücret düzeyi ve üretim maliyetleri gibi rekabet faktörleri yönünden de önemli bir avantajı bulunmaktadır. Son yıllarda dış pazarda başlayan farklı çeşit arayışları ve bölgesel özellikler taşıyan şaraplara olan ilginin giderek artması da pazar payı yaratabilme açsından etkili olabilecektir. Bu açıdan bakıldığında kaliteli şarap üretimi için öne çıkan yerel çeşitler ile dış pazarda rekabet gücü yaratılabilecektir. $\mathrm{Bu}$ nedenle kaliteli yerel çeşitlerin üretiminin teşvik edilmesi gerekmektedir. Türkiye'de şaraplık üzüm üretimiyle ilgili mevcut koşular dikkate alındığında oluşturulacak politikalar ile Fransa'da uygulanan AOC veya İtalya'daki DOC (Denominazione di Origine Controllata) sistemleri kadar katı olmasa da kaliteye ilişkin belli standartları sağlayabilecek şekilde bölge çeşit sınıflandırılmalarına gidilebilmesi mümkündür. Toprak ve iklimsel özelliklerine göre belirlenen bölgeler için üretilebilecek şaraplık üzüm çeşitleri, asma dikim sıklı̆̆ı, üretim yöntemleri, hasat sırasındaki kuru madde (şeker) ve asit miktarı, alınacak verim gibi detaylar bölgeler için ortaya konularak sınıflamalar yapılabilir. Bu çerçevede yerel çeşitler arasında yer alan Kalecik karası, Öküzgözü, Boğazkere, Karalahna, Narince, Emir kökeni kontrollü üretim açısından teşvik edilebilecek çeşitlerdir. Teşvik aşamasında üzüm çeşitlerinin kendi yöresinde kalmasına özen gösterilmesi gerekmektedir.

\section{Kaynaklar}

[1] Anonymous a, 2013 www.faostat.fao.org. Erişim tarihi: 19/10/2015

[2] Anonymous b, 2015 https://en.wikipedia.org/wiki/Grape Erişim tarihi: 21/10/2015

[3] Anonim, 2015 http://tuikapp.tuik.gov.tr/bitkiselapp/bitkisel.zul Erişim tarihi: 21/10/2015

[4] Tosun M., "Şarap Sektör Araştırması”, (SA-05-04-15)Türkiye Kalkınma Bankası A.Ş. Araştırma Müdürlüğü, 46s, Ankara, 2005

[5] Balassa B., "Trade Liberalization and Revealed Comparative Advantage", The Manchester School of Economic and Social Studies, 33, 99-123, 1965

[6] Larry M., Westgren R., Duren E., “Agribusiness Competitiveness Across National Boundaries”, American Journal of Agricultural Economics, 73 (5), 1456-1464, 1991

[7] Akgüngör S., Barbaros R.F., Kumral N., "Türk Meyve ve Sebze İşleme Sanayinin Avrupa Birliği Piyasasında Rekabet Gücü”. IV Uluslararası Ekonomi Kongresi, (METU International Conference in Economics IV), Ankara, 2000

[8] Bekmez S., Terzioğlu M., "Rekabet, Rekabet Gücü ve Rekabet Gücünü Ölçme Yöntemleri”, Türkiye Avrupa Birliği Sektörel Rekabet Analizleri, Nobel Yayınları, 17s, Ankara, 2008

[9] Laffort J., Yönetmelikler: Appelation d'Origine Controlee” (AOC) (Kökeni Kontrollü Adlandırma), Şarap ve Şarapçılık Dosyası, Kavaklıdere Firması, Ankara, 1996 